\begin{tabular}{|c|l|}
\hline Title & $\begin{array}{l}\text { MOVABLE COGNITIVE STUDIES WITH A PORTABLE, TELEMETRIC NEA R-INFRA RED SPECTROSCOPY } \\
\text { SYSTEM }\end{array}$ \\
\hline Author(s) & HOSHI, YOKO; CHEN, SHING-JEN; LIU, A I-QIN; TA MURA, MA MORU \\
\hline Citation & 乳幼児発達臨床センター年報, 23, 21-27 \\
\hline Issue Date & 2001-03 \\
\hline Doc URL & http:/hdl.handle.net/2115/25347 \\
\hline Type & bulletin (article) \\
\hline File Information & 23_P21-27.pdf \\
\hline
\end{tabular}

Instructions for use 


\title{
MOVABLE COGNITIVE STUDIES WITH A PORTABLE, TELEMETRIC NEAR-INFRARED SPECTROSCOPY SYSTEM
}

\author{
YOKO HOSHI \\ Tokyo Institute of Psychiatry \\ SHING-JEN CHEN, AI-QIN LIU \\ Hokkaido University \\ MAMORU TAMURA \\ Research Institute for Electronic Science, Hokkaido University
}

\begin{abstract}
Combining a wireless telemetry system and a portable near-infrared spectroscopy (NIRS) instrument, we have developed a novel movable neuroimaging system. The subject carries a miniaturized NIRS instrument $(8 \times 16 \times 4 \mathrm{~cm})$ on the back and NIRS data are sent by a wireless telemetry system to a laptop computer that can be placed distant from the experimental place. This system allows subjects to freely move about even during measurement. We applied this system to measure hemodynamic changes in the right frontal region of six young children ( 1 to 6 years old) while they were performing a Stroop-like test and/or playing with a jack-in-the-box. The children were relaxed and cooperative when they were studied, a result attributable to the fact that children's motion was not restricted and measurements were performed in an examination room not very different from an ordinary living room. Hemodynamic changes were observed during the Stroop test in children whose task performance was high. Our new system provides promise for cognitive studies on subjects who are difficult to examine with recent sophisticated neuroimaging techniques such as positron emission tomography and functional magnetic resonance imaging.
\end{abstract}

Key Words: near-infrared spectroscopy, neuroimage, children, Stroop-like test

\section{INTRODUCTION}

With the advent of modern neuroimaging techniques such as positron emission tomography (PET) and functional magnetic resonance imaging (fMRI), a great deal of functional mapping data on the human brain have been accumulated. However, most of these data are on the normal adult brain, while the brains of others such as children, the elderly, and patients with psychoneurological problems have not been fully examined. Although, unlike in PET study, radioactive substances are not used in fMRI study, it

Correspondence address for the first author:

Department of Psychophysiology, Tokyo Institute of Psychiatry, 2-1-8 Kamikitazawa, Setagayaku, Tokyo 156-8585, Japan.

E-mail : yhoshi@prit.go.jp 
requires strict motion restriction as in a PET study. To get subjects to participate in a study for long time, therefore, sedation is often required, especially in children, which can cause adverse reactions. Furthermore, the experimental environments in PET and fMRI studies are quite different from the daily one, and subjects mostly find this stressful. To gain further insights into brain functions, therefore, a new neuroimaging technique that is completely non-invasive and does not require strict motion restriction has been desired.

Near-infrared spectroscopy (NIRS) measures changes in the hemoglobin oxygenation state in the human brain non-invasively (Jöbsis, 1977). NIRS has been oriented toward use for clinical monitoring of tissue oxygenation. However, we and others have recently demonstrated that NIRS also has the potential for neuroimaging (Hoshi and Tamura, 1993; Kato et al., 1993). NIRS instruments of several types are now commercially available. Among them, a portable NIRS instrument allows subjects to move about during measurement like portable ECG and EEG instruments. Since data are recorded into a memory card interface in this system, however, they are not displayed in real time. We have therefore combined a wireless system with this portable NIRS instrument so that we can see data in real time at a place which is distant from the subject. It was expected that this NIRS system would enable activation studies on freely-moving subjects. To examine the performance and possibilities of this system, we measured the frontal region in young children while they were performing the Stroop test and/or playing with a jackin-the-box.

\section{THE PORTABLE NIRS MEASUREMENT SYSTEM}

The details of the portable NIRS instrument used here (HEO 200, Omron Ltd. Inc., Japan) have been reported elsewhere (Shiga et al., 1997). Briefly, it consists of a main unit and a probe unit. The main unit consists of a one-chip central processing unit (CPU), a light-emitting diode (LED) driver, an amplifier, a memory card interface, a liquid crystal display, and a power source. The probe unit, molded in elastic black silicon rubber, has a photodiode in the center and two-wavelength (760 and $840 \mathrm{~nm})$ near-infrared LEDs on either side. The distance between the photodiode and the LEDs is $3 \mathrm{~cm}$. By measuring absorbance changes at $760 \mathrm{~nm}$ and $840 \mathrm{~nm}$, relative concentration changes in oxygenated $(0 x y-\mathrm{Hb})$ and deoxygenated hemoglobin $($ deoxy-Hb) are calculated every 0.5 seconds. Although only two wavelengths are used for calculation, the algorithm used here is essentially the same as the one employed in our three-wavelength method (Hazeki and Tamura, 1988). Summation of changes in oxy-Hb and deoxy-Hb provides the relative concentration change in total hemoglobin $(\mathrm{t}-\mathrm{Hb})$, which is an indicator of the change in blood volume within an illuminated area. This instrument is connected to the transmitter of a wireless system by an RS-232C cable. The size of the NIRS instrument $(8 \times 16 \times 4 \mathrm{~cm})$ is as small as the transmitter of the wireless system (Fig. 1). These are packed in a small bag which a subject carries on the back. NIRS signals are sent by wireless to the receiver, which is connected to a laptop computer, by which data are displayed in real time. NIRS signals can be transferred to a place at a maximal distance of $30 \mathrm{~m}$ outside, but about $10 \mathrm{~m}$ in a building. 


\section{METHODS AND SUBJECTS}

The subjects were six healthy children, aged 1 to 6 years (three girls, three boys). Four of the six children ( 5 or 6 years) went to a kindergarten associated with the Faculty of Education of Hokkaido University. They had no clinical signs of brain disorders. Parental informed consent was obtained prior to the beginning of the study.

Measurements were performed in a room that looked like an ordinary living room. Examiners were a teacher and his assistant who were familiar with the children. The probe was placed on the medial side of the right forehead so that the right frontal polar cortex was mainly measured. Carrying the bag in which a portable NIRS instrument and the transmitter of the wireless system were packed on the back, children sat on a chair or a couch. The receiver and a laptop computer were placed in an adjacent room, where the children were observed by a closed-circuit television.

The four kindergarten children who could perfectly read Japanese syllabic characters ('hiragana') performed a Stroop-like test. The examiner showed a card in which the name of color was written in 'hiragana' in a different color (e. g., RED written in green ink). Ignoring the words, the children named the colors of the ink as quickly and accurately as possible. They performed the Stroop test twice with an interval of about 15 seconds. As a control study, they read 'hiragana' written in black ink before the Stroop test. Each child was trained to perform both the control task and the Stroop test several times before the investigation.

After the Stroop test, hemodynamic responses to a jack-in-the-box were examined in the four kindergarten children and a three-year-old boy. Rotating the handle of the box produced a melody and a doll suddenly appeared from the box. The examiner or children themselves rotated the handle. The one-year three-month-old girl was monitored only when playing with her mother.

To determine whether changes observed during performing a task were significant, values for $\mathrm{oxy}^{-\mathrm{Hb}}$, deoxy $-\mathrm{Hb}$, and $\mathrm{t}-\mathrm{Hb}$ during the activation period were compared with those during the resting period just before the activation period using paired-t-test for each subject. The degree of changes in Hb oxygenation during the Stroop test was compared with that during the control task by Student's $t$-test. $\mathrm{P}<0.01$ was chosen as the level of significance.

\section{RESULTS}

The examination time was about 30 minutes in all children except the one-year-old infant, who was monitored for about 10 minutes. No children felt uncomfortable during measurements and all were cooperative.

Figure 1A shows an example of NIRS traces obtained from a 5-year-old girl during performing the Stroop test. While reading each character, oxy-Hb and $\mathrm{t}-\mathrm{Hb}$ increased and deoxy-Hb decreased $(\mathrm{p}<0.001)$. Compared with these changes, the first Stroop test caused much larger increases in oxy- $\mathrm{Hb}$ and $\mathrm{t}-\mathrm{Hb}$ and a decrease in deoxy-Hb. These changes did not return to the pre-task level immediately after the cessation of the first task, and the second Stroop test did not cause further changes in Hb. The same pattern of changes was also observed in the other 5-year-old girl. Two 6-year-old boys showed increases in $\mathrm{t}-\mathrm{Hb}$ and $\mathrm{oxy}-\mathrm{Hb}$ with a decrease in deoxy- $\mathrm{Hb}$ while reading each character 
$(\mathrm{P}<0.001)$. One, whose task performance was poor, showed no change in $\mathrm{Hb}$ oxygenation during the Stroop test. The other also showed no significant change in Hb oxygenation during the first Stroop test, in which task performance was poor, while increases in oxy- $\mathrm{Hb}$ and $\mathrm{t}-\mathrm{Hb}$ with a decrease in deoxy-Hb were observed during the second one $(\mathrm{P}<$ 0.001 , Fig. 1B). However, the degree of changes in $\mathrm{Hb}$ oxygenation during the second Stroop test was the same as the degree of those during reading.

All kindergarten children but one showed no response to the jack-in-the box. One boy showed increases in $\mathrm{t}-\mathrm{Hb}, \mathrm{oxy}-\mathrm{Hb}$, and deoxy-Hb only at the first trial. But, the following trials did not cause any changes in $\mathrm{Hb}$ oxygenation. They said that they had not been startled. In contrast, the three-year-old boy showed rapid increases in deoxy- and $\mathrm{t}-\mathrm{Hb}$ when responding to the jack-in-the-box, while a significant increase in $\mathrm{oxy}^{-\mathrm{Hb}}$ was not observed (Fig. 2). Similar responses were observed at all three trials, where the magnitude of changes in $\mathrm{Hb}$ was also almost the same. Since he was very scared, he showed increases in deoxy- and $\mathrm{t}-\mathrm{Hb}$ even when the doll did not appear yet. We also measured two adults to examine whether this lack of response was related to age. They showed increases in $\mathrm{oxy}^{-} \mathrm{Hb}$ and $\mathrm{t}-\mathrm{Hb}$ with a decrease in deoxy-Hb (data not shown).

\section{DISCUSSION}

The present study demonstrated that even young children cooperatively participated in cognitive studies, when children's motion was not restricted and measurements were performed in an examination room which looked like an ordinary living room. It was also demonstrated that although severe motion restriction was absent, the portable NIRS system could detect task-related hemodynamic changes. In the present study, three children showed increases in $\mathrm{oxy}-\mathrm{Hb}$ and $\mathrm{t}-\mathrm{Hb}$ with a decrease in deoxy-Hb during the Stroop test. This suggested that $\mathrm{rCBF}$ increased in the right frontal polar cortex, although it was not examined by 3-D MRI which part of the brain was underneath the probe placed on the head surface. The Stroop test is a classic paradigmatic measure of attention and interference (Stroop, 1935 ; Macleor, 1991). It has been reported that the right frontal polar cortex, which is associated with selective attention, is activated during the Stroop color naming test (Bench et al., 1993 ; Carter et al., 1995). The fact that no significant changes in $\mathrm{Hb}$ oxygenation were observed in two boys could be explained by their poor task performance. However, in two girls the second Stroop test did not cause further changes in $\mathrm{Hb}$ oxygenation, which had not returned to the pre-task levels after the cessation of the first trial (Fig. 3A). Factors such as anxiety, confusion, and anticipation of the task are inherent in subjects, unless they get to perform the task successfully by repeating trials. It is conceivable that such emotional factors were mainly responsible for the increase in $\mathrm{rCBF}$ observed in these girls. This might also explain the observation that the degree of changes in $\mathrm{Hb}$ oxygenation during the second Stroop test was the same as the degree of those during reading in the 6-year-old boy (Fig. 3B). With a careful paradigm design and placing the probe at a proper position, however, it is possible to detect the brain activation specifically associated with attention. A multichannel NIRS system of the present type, which we are now developing, will not only provide information about multiple brain regions but also be useful to find a proper position of the probe.

There are only a few ways of evaluating the cognitive ability of neonates and 
younger infants, who cannot speak yet or perform tasks. Changes in facial expressions and physiological parameters such as the heart rate are often used as indicators of cognition in these subjects (Trevarthen, 1998). For example, whether a baby can distinguish the baby's mother from others is judged from the facial expression. In general, the
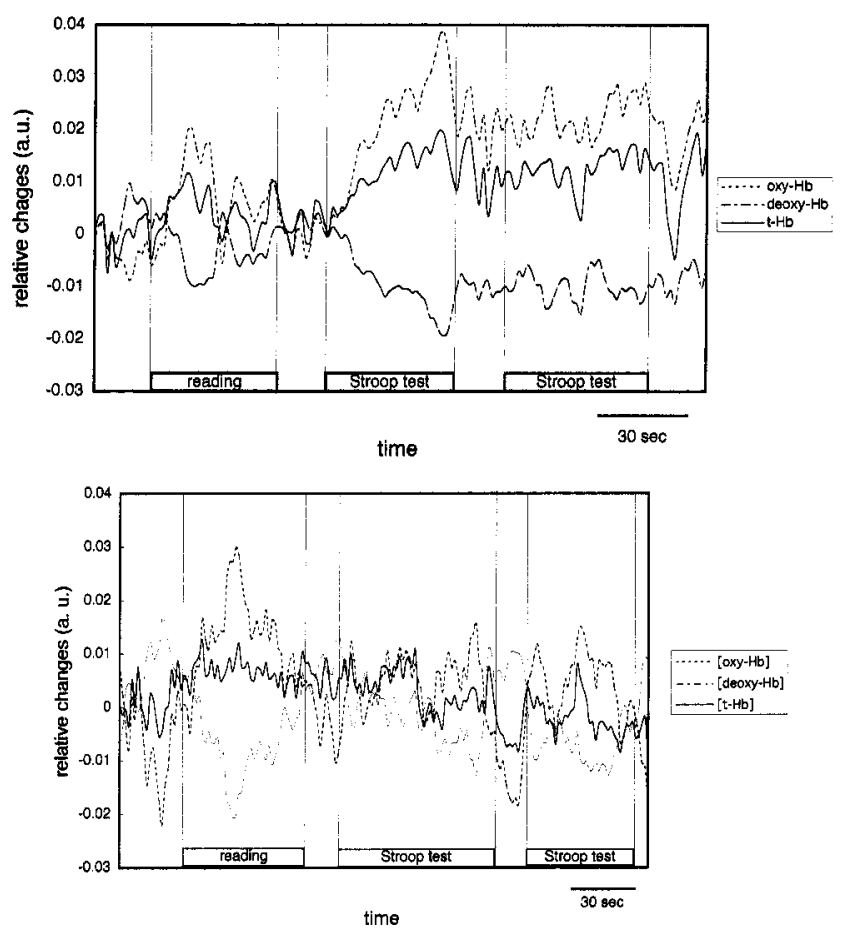

Figure 1 Relative concentration changes in oxygenated (oxy-Hb), deoxygenated (deoxy-Hb), and total hemoglobin $(\mathrm{t}-\mathrm{Hb})$ in the right frontal region while a 5-year-old girl (A) and a $6^{-}$yearold boy (B) performed the Stroop test. Baselines were selected from resting state, and these values were taken as zero for each signal. Changes from baseline are represented as relative amounts. Upward (plus) and downward (minus) trends show increase and decrease in values, respectively.

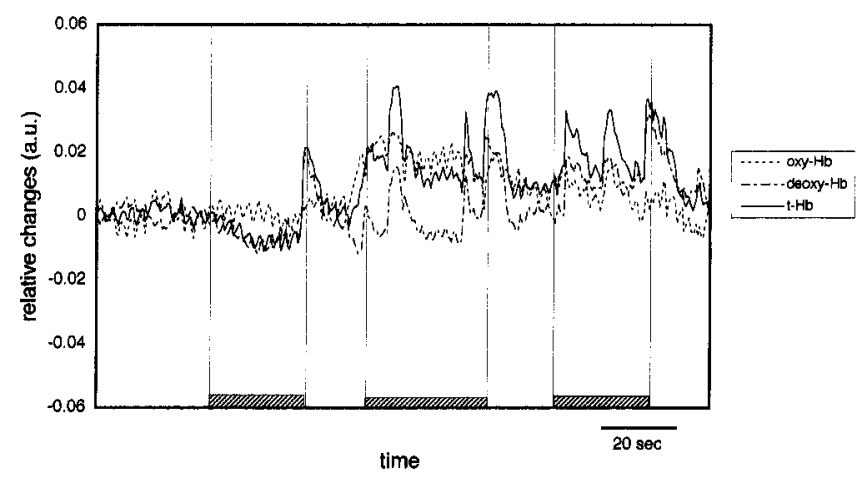

Figure 2 Relative concentration changes in $\mathrm{oxy}^{-}$, deoxy-, and t-Hb while a 3-year-old boy was playing with a jack-in-the-box. The shaded bar denotes time when the handle of the box was being rotated. 
cognitive operations are accompanied by emotional changes. It is, thus, expected that by detecting brain activation associated with emotion, the cognitive ability can be objectively evaluated. Emotions are thought to be associated with activation of the medial frontal cortex (Lane et al., 1997). In the present study, however, four kindergarten children did not show any changes in $\mathrm{Hb}$ oxygenation while playing with the jack-in-the-box. In contrast, hemodynamic responses were observed in the three-year-old boy and adults. There might be differences in the neural basis of being startled between children of this age and others. Unlike adults, however, this three-year-old boy showed no significant increase in oxy-Hb comapred with those in $\mathrm{t}-\mathrm{Hb}$ and deoxy-Hb. Recent fMRI and NIRS studies reported a stimulus-related increases in deoxy-Hb in neonates and infants (Born et al., 1998; Meek et al., 1998; Hoshi et al., 2000). However, the degree of increases in deoxy- $\mathrm{Hb}$ was smaller than that in $0 x y^{-} \mathrm{Hb}$ in these previous NIRS studies. At the moment, the absence of significant increases in $0 x y-H b$ in this boy are unexplained.

Although further investigation is required to give valid explanations for these results, it is emphasized that only our system can detect such hemodynamic changes when children are playing. In addition, hemodynamic changes could be monitored in a oneyear-old infant when she was playing with her mother. This suggests that the present system has the potential to investigate cognition in neonates and infants by measuring hemodynamic changes related to emotions.

The direction of recent functional mapping studies is toward exploring more precise aspects of brain functions such as the components of working memory (Choen et al., 1997) and the sequence of brain activation (Horwitz et al., 1995). The present reported NIRS system is not suitable for this purpose, but it provides a new direction for functional mapping studies. Our newly developed system will open a window on brain physiology in subjects who have been rarely examined until now.

\section{Acknowledgement}

This work has been supported by the JSPS project (RFTR-97L0025).

\section{REFERENCES}

Bench, C. J., Frith, C. D., Grasby, P. M., Friston, K. J., Paulsesu, E., Frackowiak, R. S. J., and Dolan, R. J. (1993). Investigations of the functional anatomy of attention using Stroop test. Neuropsy. chologia, 31, 907-922.

Born, P., Leth, H., Miranda, M. J., Rostrup, E., Stensgaard, A., Peiterson, B., Larsson, H. B. W., and Lou, H.C. (1998). Visual activation in infants and young children: studies by functional magnetic resonance imaging. Pediatric Reseach, 44, 578-583.

Carter, C. S., Mintum, M., and Cohen, J. D. (1995). Interference and facilitation effects during selective attention: an H215O PET study of Stroop task performance. NeuroImage, 2, 264-272.

Choen, J.D., Perlstein, W. M., Braver, T. S., Nystrom, L.E., Noll, D.C., Jonides, J., and Smith E. E. (1997). Temporal dynamics of brain activation during a working memory task. Nature, 386, 604-607.

Hazeki, O. and Tamura, M. (1988). Quantitative analysis of hemoglobin oxygenation state of rat brain in situ by near-infrared spectrophotometry. Journal of Appllied Physiology, 64, 796-802.

Horwitz, B., Mcintosh, A. R., Haxby, J. V., Furey, M., Salerno, J. A., Schapiro, M. B., Rapoport, S. I., and Grady, C. L. (1995). Network analysis of PET-mapping visual pathways in Alzheimer type dementia. Neuroreport, 6, 2287-2292. 
Hoshi, Y. and Tamura, M. (1993). Detection of dynamic changes in cerebral oxygenation coupled to neuronal function during mental work in man. Neuroscience Letter, 150, 5-8.

Hoshi, Y., Kohri, S., Matsumoto, Y., Chou, K., Matsuda, T., Okajima, S., and Fujimoto, S. (2000). Hemodynamic responses to photic stimulation in neonates. Pediatric Neurology, 23, 323-327.

Jöbsis, F.F. (1977). Noninvasive, infrared monitoring of cerebral and myocardial oxygen sufficiency and circulatory parameters. Science, 198, 1264-1267.

Kato, T., Kamei, A., Takashima, S., and Ozaki, T. (1993). Human visual cortical function during photic stimulation monitoring by means of near-infrared spectroscopy. Joumal of Cerebral Blood Flow Metabolism, 13, 516-520.

Lane, R. D., Reiman, E. M., Bradley, M. M., Lang, P. J., Ahren, G. L., Davidson, R. J., and SCHWARTZ, G.E. (1997). Neuroanatomical correlates of pleasant and unpleasant emotion. Neuropsychologia, 35, 1437-1444.

Macleod, C. M. (1991). Half a century of research on the Stroop effect: an integrative review. Psycho. logical Bulletin, 109, 163-203.

Meek, J. H., Firbank, M., Elwell, C.E., Atkinson, J., Bradick, O., and Wyatt, J.S. (1998). Regional hemodynamic response to visual stimulation in wake infants. Pediatric Research, 43, 840-843.

Shiga, T., Yamamoto, K., Tanabe, K., Nakase, Y., and Chance, B. (1997). Study of an algorithm based on model experiments and diffusion theory for a portable tissue oximeter. Journal of Biomedical Optics, 2, 154-161.

Stroop, J. R. (1935). Studies of interference in serial verbal reactions. Joumal of Experimental Psychol. ogy, 18, 643-662.

Trevarthen, C. (1998). The concept and foundation of infant intersubjectivity. In S. Bråten (Ed.), Intersubjective Communication and Emotion Early Ontology. Pp. 15-46. Cambridge : Cambridge University Press. 